\title{
Innovative Silicon Compatible Materials for Light Emitting Devices
}

\author{
Adriana Scarangella1, Riccardo Reitano ${ }^{2}$, Francesco Priolo ${ }^{1,2,3}$, Maria Miritello ${ }^{1 *}$

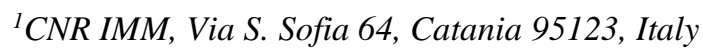 \\ ${ }^{2}$ Dipartimento di Fisica e Astronomia, Università di Catania, Via S. Sofia 64, Catania 95123, Italy \\ ${ }^{3}$ Scuola Superiore di Catania, Università di Catania, Via Valdisavoia 9, Catania 95123, Italy \\ *Corresponding author: E-mail: maria.miritello@ct.infn.it
}

Received: 19 September 2018, Revised: 15 October 2018 and Accepted: 19 October 2018

DOI: $10.5185 /$ amlett.2019.2276

www.vbripress.com/aml

\begin{abstract}
The paper reports the potentialities of innovative silicon compatible materials for light emitting devices. In particular thin films of Er doped yttrium oxide have been synthesized by a technique totally compatible with ULSI processes. Through the structural characterization, we will verify the high stability of the film and the good dopant dissolution. Moreover, by the investigation of the optical properties, we will demonstrate that the use of this compound is effective to introduce more than $10^{21} \mathrm{Er} / \mathrm{cm}^{3}$ in optically active state, value that cannot be reached in other Si compatible materials. The influence of Er content on the optical properties will be described in details. Moreover, we will propose the introduction of a proper sensitizer for Er, bismuth, in the same thin film. In particular, we will show that the (Er+Bi) co-doped yttrium oxide is a perfect host to overcome another important drawback of Er doped materials that is its low absorption cross section. The influence of $\mathrm{Bi}$ and $\mathrm{Er}$ contents on optical properties will be extensively discussed along the paper. Through the optimization of ratio between $\mathrm{Bi}$ and $\mathrm{Er}$ concentrations, high energy transfer efficiency will be reached with simultaneously a consistent increase of the effective Er cross section. A factor of more than three orders of magnitude have been obtained with respect to the direct excitation of Er. Copyright $\odot$ VBRI Press.
\end{abstract}

Keywords: Light emitting devices, erbium, yttrium oxide.

\section{Introduction}

In the last decades, the limitations reached by silicon microelectronics brought the scientific community to move towards the field of silicon photonics with the aim to use photons instead of electrons for carrying and processing information inside a Si chip $[\mathbf{1 , 2}]$. Among the investigated optically active Si-compatible media, erbium-based materials have been extensively studied since Er de-excitation, from ${ }^{4} \mathbf{I}_{13 / 2}$ to ${ }^{4} \mathrm{I}_{15 / 2}$ level, involves the emission of a photon at $1.54 \mu \mathrm{m}$ that corresponds to a minimum loss of silica optical fibers [1-3]. However, its excitation cross section of about $10^{-21} \mathrm{~cm}^{2}$ [4] is a limiting factor to achieve high optical efficiency, and at the same time introducing a high number of Er ions in Si-compatible materials is still challenging owing to low Er solid solubility [5]. To overcome these limits, successful approaches have been recently pursued. The first one concerns the development of mixed rare earth (RE) oxides or silicates, where Er-based materials have been employed [7-11]. Here it is possible to control in a continuous way the Er content up to $10^{22} \mathrm{Er} / \mathrm{cm}^{3}$, without cluster formation and also by limiting detrimental Er-Er interactions such as concentration quenching [12-14]. Among all the mixed RE compounds, yttrium oxide is a good candidate as host for Er, owing to its comparable crystalline structure with respect to one of Er oxide and to the similar Er and $\mathrm{Y}$ ionic radii. Moreover, $\mathrm{Y}^{3+}$ is not optically active, thus giving transparency properties to its compound from the visible to the infrared (IR) range and permitting to assign all the material's optical properties to Er ions. In addition, thanks to the development of complementary metal-oxide-semiconductor (C-MOS) compatible synthesis techniques, it is possible to realize good quality thin films with high thermal stability on silicon [15]. Thus, Er doped yttrium oxides have reached great attention for the realization of CMOScompatible Si-based light sources operating at room temperature (RT). The second strategy to further increase the Er optical efficiency in Si-compatible materials is to enhance the low Er excitation cross section, with the introduction of a proper sensitizer that can absorb and transfer the energy more efficiently than Er ions. Successful results have been reached by the development of luminescent Si nanostructures, such as Si nanowires [16] and Er-coupled Si nanoclusters [1, 17], that have been demonstrated to be optically efficient both under optical and electrical pumping at RT. However up to now the reached efficiency is still not enough for commercial devices. Despite other REs have been already proposed as Er sensitizers, such as $\mathrm{Yb}^{3+}[\mathbf{1 8}]$, recently the use of optically active metal ions, such as bismuth, as REs sensitizer emitting in the 
visible wavelength range is reported [19-21]. However, very few papers report the occurrence of energy transfer (ET) between $\mathrm{Bi}$ and Er ions [22-25].

In this paper we propose the use of both approaches, i.e. the Er doped yttrium oxide thin films to dissolve high concentrations of active centers in a Si compatible host and at the same time the introduction of $\mathrm{Bi}$ as an $\mathrm{Er}$ sensitizer as a suitable material for light emission. The structural and optical properties of $\mathrm{Er}$ and $\mathrm{Bi}$ co-doped yttrium oxide thin films will be discussed, by focusing on the dependence by the Er and Bi concentrations. The stability of the films and the dopants dissolution in the host will be analyzed. Moreover, we will treat the coupling of Er and Bi by investigating the best Er and $\mathrm{Bi}$ ratio to maximize the optical efficiency of the system.

\section{Experimental}

\section{Material synthesis}

Er doped $\mathrm{Y}_{2} \mathrm{O}_{3}$ thin films were deposited by AJA UHV magnetron co-sputtering (base pressure $10^{-9} \mathrm{mbar}$ ). All the depositions have been performed in argon atmosphere $\left(5 \times 10^{-3}\right.$ mbar $)$ by radio frequency cosputtering of two targets $\left(\mathrm{Y}_{2} \mathrm{O}_{3}\right.$ and $\left.\mathrm{Er}_{2} \mathrm{O}_{3}\right)$ on c-Si(100) substrates heated at $400{ }^{\circ} \mathrm{C}$. The power applied to the $\mathrm{Y}_{2} \mathrm{O}_{3}$ target was fixed at $500 \mathrm{~W}$, while that one to the $\mathrm{Er}_{2} \mathrm{O}_{3}$ target was varied between $25 \mathrm{~W}$ and $40 \mathrm{~W}$. Some samples have been implanted with $\mathrm{Bi}$ ions at $270 \mathrm{keV}$, the energy has been chosen in order to locate the $\mathrm{Bi}$ distribution almost in the center of the films thickness, as calculated by Stopping and Range of Ions in Matter (SRIM) simulations [26].

Both the Er doped and $(\mathrm{Er}+\mathrm{Bi})$ co-doped samples have then be annealed at $800{ }^{\circ} \mathrm{C}$ for $30 \mathrm{~min}$ in oxygen atmosphere to stabilize the $\mathrm{Bi}^{3+}$ and $\mathrm{Er}^{3+}$ oxidation state and to remove eventual defects left over by the implantation process.

\section{Characterizations}

The films stoichiometry, elemental concentration and thickness have been evaluated by Rutherford BackScattering Spectrometry (RBS). RBS measurements have been performed by using a $2 \mathrm{MeV}$ energy $\mathrm{He}^{+}$ beam with the detection at an angle of $165^{\circ}$ with respect to the beam direction.

The crystalline structure of the samples has been studied by X-Ray Diffraction (XRD) analyses performed with a Bruker-AXSD5005 diffractometer by using $\mathrm{Cu} \mathrm{K} \alpha$ radiation with a grazing incidence angle of $1.0^{\circ}$ and the detection angle $2 \theta$ varied between $18^{\circ}$ and $60^{\circ}$.

The optical properties of all the annealed films have been analyzed by photoluminescence (PL) measurements at room temperature. The $488 \mathrm{~nm}$ line of an Ar laser was chosen because in resonance with the ${ }^{4} \mathrm{I}_{15 / 2} \rightarrow{ }^{4} \mathrm{~F}_{7 / 2} \mathrm{Er}^{3+}$ transition, while the $325 \mathrm{~nm}$ line of an $\mathrm{He}-\mathrm{Cd}$ laser was chosen as pumping source, because it could permit to excite the UV band of all the possible $\mathrm{Bi}$ oxidation states. In both cases, the laser beam was chopped through an acousto-optic modulator with a frequency of $11 \mathrm{~Hz}$. PL signals have been recorded by a three gratings monochromator and a lock-in system modulated at the same chopping frequency. The PL spectra were analyzed in the range between $400 \mathrm{~nm}$ and $1700 \mathrm{~nm}$ thanks to water cooled photomultiplier and a liquid nitrogen-cooled Ge detector. Time resolved PL measurements were performed by detecting the modulated PL signal with a Hamamatsu photomultiplier tube and then by analyzing the signal with a photon counting multichannel scaler. The overall time resolution of the system is $30 \mathrm{~ns}$.

\section{Results and discussion}

\section{Structural properties}

In this section we report the structural properties of the Er and $(\mathrm{Er}+\mathrm{Bi})$ co-doped yttrium oxide thin films. First of all, the stoichiometry of the films and the elemental concentration of both the dopants, $\mathrm{Er}$ and $\mathrm{Bi}$, have been evaluated by RBS measurements. Fig. 1 reports the RBS spectra of the two annealed Er doped $\mathrm{Y}_{2} \mathrm{O}_{3}$ oxide thin films synthesized with the same power supplied to the $\mathrm{Y}_{2} \mathrm{O}_{3}$ target and different powers applied to the $\mathrm{Er}_{2} \mathrm{O}_{3}$ target, in particular $25 \mathrm{~W}$ and $40 \mathrm{~W}$.

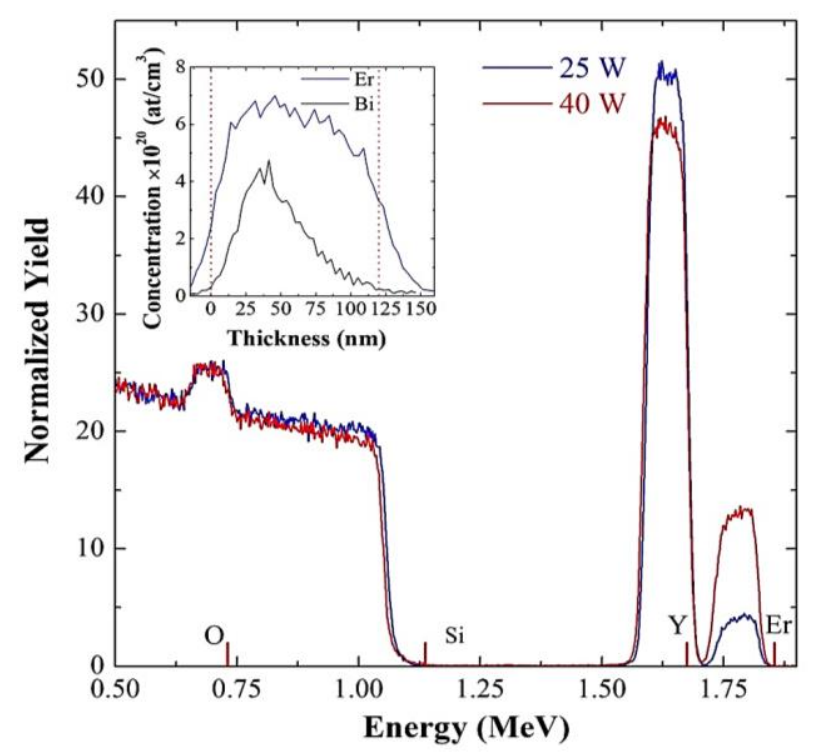

Fig. 1. RBS spectra of Er doped $\mathrm{Y}_{2} \mathrm{O}_{3}$ thin films on c-Si for different powers applied to the $\mathrm{Er}_{2} \mathrm{O}_{3}$ target. The threshold energies of $\mathrm{O}, \mathrm{Si}, \mathrm{Y}$, and $\mathrm{Er}$ are also indicated. In the insert the $\mathrm{Bi}$ and Er depth distribution profile in $(\mathrm{Er}+\mathrm{Bi})$ co-doped $\mathrm{Y}_{2} \mathrm{O}_{3}$ for higher $\mathrm{Er}$ and $\mathrm{Bi}$ contents.

Four signals are distinguishable, that can be identified as the depth profiles of $\mathrm{O}, \mathrm{Si}, \mathrm{Y}$, and $\mathrm{Er}$, as indicated by the threshold energies of the respective elements. For both samples the Si signal is relative to the silicon substrate, while all the other signals are relative to the thin film. All the signals appear constant along all the film thickness, thus demonstrating a uniform chemical composition. By simulating the RBS curves with the software SIMNRA 6.0 [27], the film stoichiometry was verified to be $(\mathrm{Y}+\mathrm{Er}): \mathrm{O}=2: 3$, and the Er content has been evaluated as $1.1 \mathrm{Er} \%$ and 3.3 
Er\% respectively for powers applied to the $\mathrm{Er}_{2} \mathrm{O}_{3}$ target of $25 \mathrm{~W}$ and $40 \mathrm{~W}$. The Er profile can be plotted, by converting the normalized yield and the energy axes, respectively, in volume concentration and depth scales. In particular, for the higher Er content the Er depth profile has been reported in the insert of Fig. 1. A constant Er concentration of about $7 \times 10^{20} \mathrm{Er} / \mathrm{cm}^{3}$ has been estimated along all the film thickness of $120 \mathrm{~nm}$, while a value of $3.0 \times 10^{20} \mathrm{Er} / \mathrm{cm}^{3}$ for the lower power applied to the $\mathrm{Er}_{2} \mathrm{O}_{3}$ target.

When $\mathrm{Bi}$ is introduced in the two films, the $\mathrm{Bi}$ signal is partially overlapped with the Er one, since the energy thresholds are $1.855 \mathrm{MeV}$ and $1.820 \mathrm{MeV}$, respectively for $\mathrm{Bi}$ and $\mathrm{Er}[\mathbf{2 8}, \mathbf{2 9}]$. Therefore, we have used as reference sample a $\mathrm{Bi}$ doped $\mathrm{Y}_{2} \mathrm{O}_{3}$ thin film implanted with the same dose and energy used for the samples under investigation. The obtained $\mathrm{Bi}$ profile has been reported in the insert of Fig. 1 for the case of higher $\mathrm{Bi}$ doping. It has the typical Gaussian shape related to the ion implantation processes, and a $\mathrm{Bi}$ content of $2.8 \times 10^{20} \mathrm{Bi} / \mathrm{cm}^{3}$ and $7.0 \times 10^{20} \mathrm{Bi} / \mathrm{cm}^{3}$ has been evaluated for the two nominal implanted doses, corresponding to the $0.4 \mathrm{Bi} \%$ and $1.0 \mathrm{Bi} \%$ respectively.

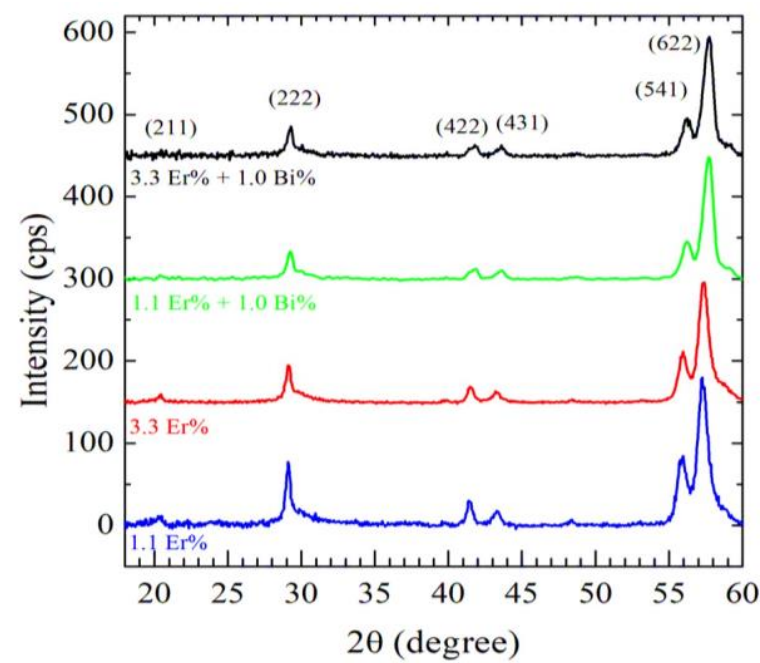

Fig. 2. XRD patterns of the $\mathrm{Y}_{2} \mathrm{O}_{3}$ thin films containing only Er and $(\mathrm{Er}+\mathrm{Bi})$ for the two used $\mathrm{Er}$ concentrations. The Miller indices corresponding to the $\mathrm{Y}_{2} \mathrm{O}_{3}$ bulk are also indicated [30].

In order to study the influence of $\mathrm{Er}$ and $\mathrm{Bi}$ incorporation in the $\mathrm{Y}_{2} \mathrm{O}_{3}$ crystalline structure, XRD analyses have been performed in glancing configuration. The XRD spectra of both Er-doped $\mathrm{Y}_{2} \mathrm{O}_{3}$ and $(\mathrm{Bi}+\mathrm{Er})$ co-doped $\mathrm{Y}_{2} \mathrm{O}_{3}$ thin films for the higher $\mathrm{Bi}$ content, 1.0 Bi\%, are shown in Fig. 2. All the spectra appear very similar, independently of the Er content and $\mathrm{Bi}$ presence. In particular they are characterized by several intense peaks, which can be all associated to the polycrystalline body centered cubic structure of $\mathrm{Y}_{2} \mathrm{O}_{3}$ [30]: The Miller indices of the corresponding lattice planes are reported in the same figure. Other additional peaks associable to the formation of other crystalline phases are absent, thus confirming the good dissolution of both dopants inside the $\mathrm{Y}_{2} \mathrm{O}_{3}$ crystalline structure. Only a slight shift of the peaks towards higher angles is observed, when $\mathrm{Bi}$ is introduced, and it was correlated to a slight shrinkage of the lattice parameter due to the larger ionic radius of $\mathrm{Bi}$ with respect to $\mathrm{Y}(1.03 \AA$ and $0.9 \AA$ respectively for $\mathrm{Bi}$ and $\mathrm{Y})$. Thus, we can support the assert that both $\mathrm{Er}$ and $\mathrm{Bi}$ can replace $\mathrm{Y}$ in substitutional positions in the $\mathrm{Y}_{2} \mathrm{O}_{3}$ lattice.
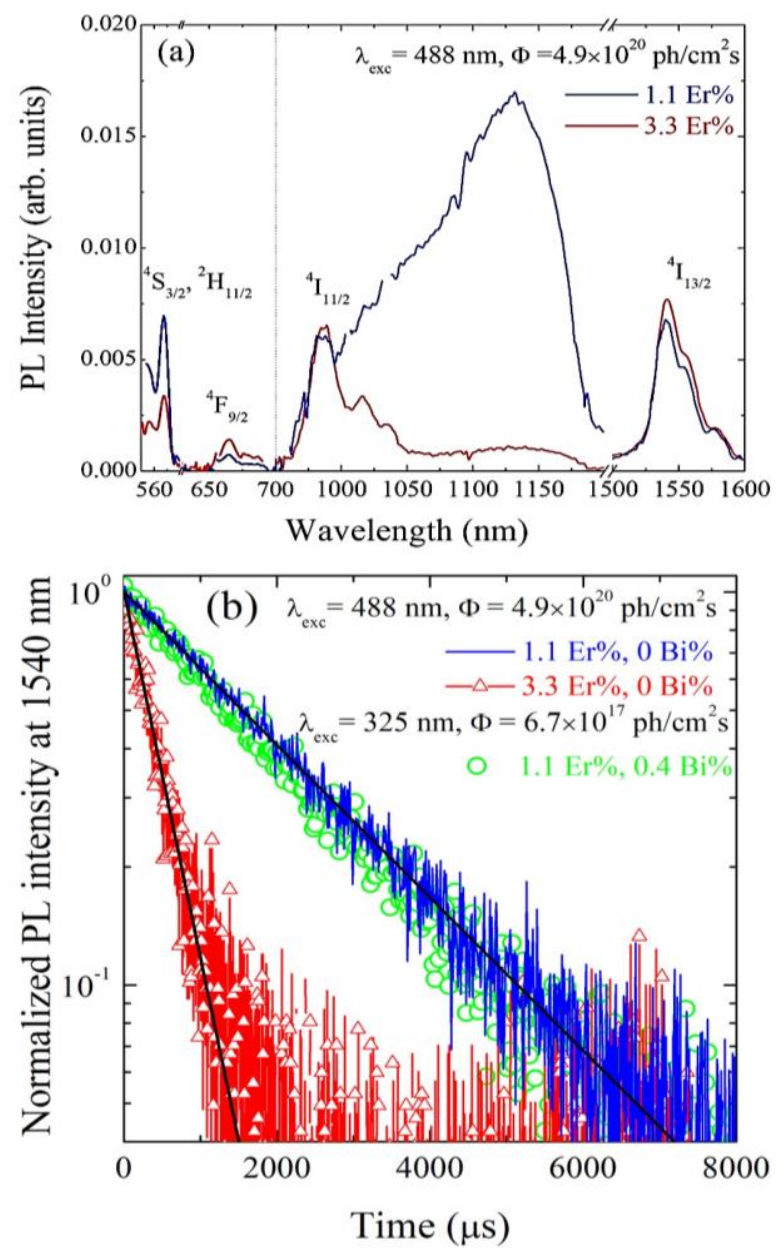

Fig. 3. (a) PL spectra over all the visible and IR range of the Er doped $\mathrm{Y}_{2} \mathrm{O}_{3}$ thin films, for the two Er contents. The measurements have been done under $488 \mathrm{~nm}$ and pump flux of $4.9 \times 10^{20} \mathrm{ph} / \mathrm{cm}^{2} \mathrm{~s}$. The Er excited levels involved for each peak PL emission are also indicated. (b) The relative time-resolved PL recorded at $1540 \mathrm{~nm}$ have been reported. In comparison also the decay curve recorded under $325 \mathrm{~nm}$ and pump flux of $6.7 \times 10^{17} \mathrm{ph} / \mathrm{cm}^{2} \mathrm{~s}$ has been plotted. The exponential fits have been also reported.

\section{Optical properties}

\section{Visible and IR emission}

The optical properties of all the annealed films have been analysed by PL and lifetime measurements at RT.

We have firstly analyzed the Er-doped $\mathrm{Y}_{3} \mathrm{O}_{3}$ thin films by using the $488 \mathrm{~nm}$ line of an Argon laser as pumping source, with a photon flux of $4.9 \times 10^{20} \mathrm{ph} /$ $\mathrm{cm}^{2} \mathrm{~s}$. This excitation wavelength permits to excite directly the ${ }^{4} \mathrm{I}_{15 / 2} \rightarrow{ }^{4} \mathrm{~F}_{7 / 2} \mathrm{Er}^{3+}$ transition. The PL spectra obtained for $1.1 \mathrm{Er} \%$ and $3.3 \mathrm{Er} \%$ have been shown in Fig. 3 (a): different emission peaks are detected in the visible and IR region, in particular centred at $566 \mathrm{~nm}$, $660 \mathrm{~nm}, 980 \mathrm{~nm}$ and $1540 \mathrm{~nm}$, that correspond 
respectively to the $\mathrm{Er}^{3+}$ transitions from $\left({ }^{4} \mathrm{~S}_{3 / 2},{ }^{2} \mathrm{H}_{11 / 2}\right)$, ${ }^{4} \mathrm{~F}_{9 / 2},{ }^{4} \mathrm{I}_{11 / 2}$ and ${ }^{4} \mathrm{I}_{13 / 2}$ to the ${ }^{4} \mathrm{I}_{15 / 2}$ ground state. The additional broad emission peaked at $1140 \mathrm{~nm}$ is not ascribed to Er emission but rather to the Si band edge emission from the oxidized silicon interface, that typically can be formed. The presence of all the radiative emission peaks is made possible by the long radiative lifetimes that characterize the $\mathrm{Y}_{2} \mathrm{O}_{3}$ host $[14$.

By the comparison of the two samples, we can observe an increase of PL at $566 \mathrm{~nm}$ and a simultaneous decrease of PL at $660 \mathrm{~nm}$ by increasing Er content. The reduction of the green emission despite the increase of the Er emitting centers can be justified by a corresponding increase of the nonradiative decay rate of the ${ }^{4} \mathrm{~S}_{3 / 2}$ level, owing to the occurrence of the cross relaxation (CR) ${ }^{4} \mathrm{~S}_{3 / 2}+{ }^{4} \mathrm{I}_{15 / 2} \rightarrow{ }^{4} \mathrm{I}_{9 / 2}+{ }^{4} \mathrm{I}_{13 / 2}$ [14]. Since the $\mathrm{CR}$ mechanism is an energy transfer process between one excited Er ion and another one in the ground state, it becomes more probable by reducing the Er-Er distance, i.e. by increasing the Er content [14].

Instead, in the IR range, we observe similar PL intensities both at $980 \mathrm{~nm}$ and $1540 \mathrm{~nm}$ for both samples, despite the 3-fold increase of Er content. In order to explain it, we have acquired also the decay times of the PL at $1540 \mathrm{~nm}$ that have been reported in Fig. 3 (b) for both the Er concentrations. Both curves have a single exponential decay, thus by proper fits, values of $2.2 \mathrm{~ms}$ and $0.5 \mathrm{~ms}$ have been found respectively for $1.1 \mathrm{Er} \%$ and $3.3 \mathrm{Er} \%$. The observed reduction of the Er lifetimes at $1540 \mathrm{~nm}$ with increasing the Er concentration may be explained by the occurrence of up conversion (UC) phenomena, well known in Er-doped systems [11, 12]. The UC mechanism consists in resonant energy transfer between excited Er ions, ${ }^{4} \mathrm{I}_{13 / 2}+{ }^{4} \mathrm{I}_{11 / 2} \rightarrow{ }^{4} \mathrm{I}_{15 / 2}+{ }^{4} \mathrm{~F}_{9 / 2}$. By increasing the Er ions during the light travel through the host the probability that the energy can be lost to impurities, such as -OH centers, increases $[5,12,32]$, by dissipating it non-radiatively. Thus, the reduction of lifetime, by a factor of 4 , justifies the presence of similar PL values at $1540 \mathrm{~nm}$, despite the Er concentration increase from $1.1 \%$ to $3.3 \%$.

The introduction of $\mathrm{Bi}$ in the Er doped $\mathrm{Y}_{2} \mathrm{O}_{3}$ does not induce any modification in the PL spectra and also the intensities are unchanged with respect to the Er: $\mathrm{Y}_{2} \mathrm{O}_{3}$ case when the system is excited under $488 \mathrm{~nm}$. Instead if we choose the $325 \mathrm{~nm}$ excitation wavelength, that can involve the ${ }^{1} \mathrm{~S}_{0} \rightarrow{ }^{3} \mathrm{P}_{1}$ transition of $\mathrm{Bi}^{3+}$ ions as reported in [33-35], we observe PL emission from Er ions though this excitation wavelength is out of resonance of any Er energy levels. Fig. 4 (a) reports the PL spectra of (Er+Bi) co-doped samples under $325 \mathrm{~nm}$ for both the Er and $\mathrm{Bi}$ contents. The used photon flux is $6.7 \times 10^{17} \mathrm{ph} / \mathrm{cm}^{2} \mathrm{~s}$ that is almost three orders of magnitude lower than the one used under $488 \mathrm{~nm}$ excitation.

For all the $(\mathrm{Er}+\mathrm{Bi})$ co-doped samples, all the peaks associable to the Er transitions have been detected, but with much higher intensities, about three orders of magnitude, with respect to the case of Er-doped films under resonant excitation, if normalized for the used pump fluxes. Moreover, in the visible range a further broad band appears overlapped to the Er peaks. The origin of this band can be associated to PL emission from the $\mathrm{Bi}$ ions that are not coupled with $\mathrm{Er}$ ones. In particular it can be ascribed to the optical transition between the excited state ${ }^{3} \mathrm{P}_{1}$ to the ground state ${ }^{1} \mathrm{~S}_{0}$ [36-38], as depicted in the schema reported in Fig. 4 (b). However, the Bi PL emission intensity is strongly decreased compared with the one from similar samples that contain only $\mathrm{Bi}$ and not $\mathrm{Er}$, used as references (not shown). Therefore the simultaneous reduction of the Bi PL intensities and the appearance of all the typical Er emission peaks suggest the occurrence of efficient ET mechanisms from $\mathrm{Bi}$ to Er ions, owing to the already demonstrated good overlap between the excitation band of $\mathrm{Bi}$ ions in $\mathrm{Bi}: \mathrm{Y}_{2} \mathrm{O}_{3}$ and of Er ions in $\mathrm{Bi}+\mathrm{Er}: \mathrm{Y}_{2} \mathrm{O}_{3}[39,41]$ as depicted in Fig. 4 (b). The higher Er PL intensities have been reached for $1.1 \mathrm{Er} \%$ and $1.0 \mathrm{Bi} \%$.

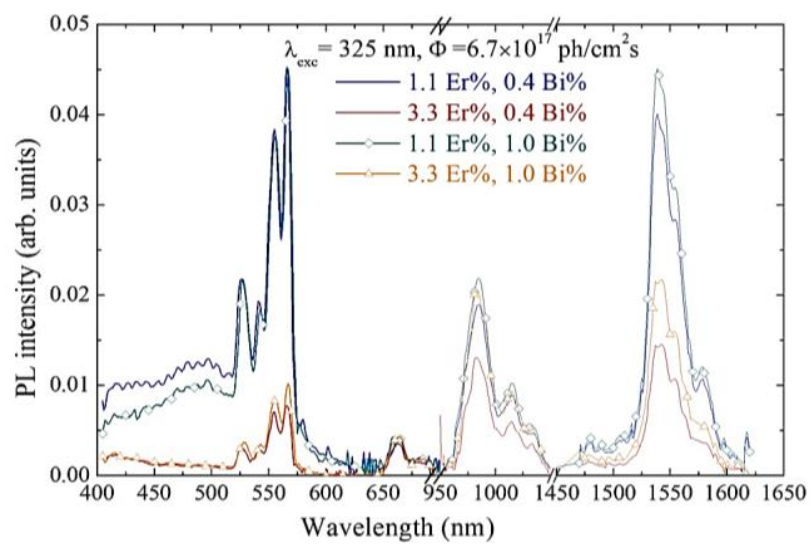

(a)

(b)

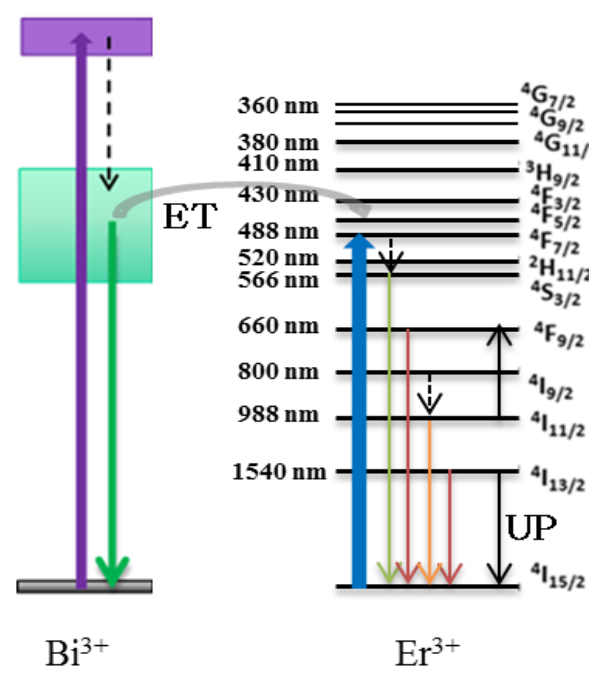

Fig. 4. (a) PL spectra over all the visible and IR range of (Er+Bi) codoped samples under $325 \mathrm{~nm}$ excitation and pump flux of $6.7 \times 10^{17}$ $\mathrm{ph} / \mathrm{cm}^{2} \mathrm{~s}$, by varying the $\mathrm{Er}$ and $\mathrm{Bi}$ concentrations. (b) Er and $\mathrm{Bi}$ energy levels schema reporting the most important optical transitions, i.e. Bi excitation under $325 \mathrm{~nm}$ wavelength, $\mathrm{Bi}$ radiative and nonradiative (ET) de-excitation, direct $\mathrm{Er}$ excitation under $488 \mathrm{~nm}$ wavelength, Er radiative emissions and UP (6). 
To further unveil the efficiency of the ET process, we have verified that the presence of $\mathrm{Bi}$ does not influence the Er lifetime for all the involved emission peaks and for all the investigated $\mathrm{Bi}$ and $\mathrm{Er}$ concentrations. In Fig. 3 (b) we compare the Er decay time at $1540 \mathrm{~nm}$ for the case of $1.1 \mathrm{Er} \%$ and $0.4 \mathrm{Bi} \%$ observed under $325 \mathrm{~nm}$ excitation with the one from $\mathrm{Er}$ doped sample, containing the same $\mathrm{Er}$ content, observed under resonant excitation. The curves appear clearly unchanged. It means that $\mathrm{Bi}$ ions do not introduce any further non-radiative channels to $\mathrm{Er}$ deexcitation, and the energy transfer between $\mathrm{Bi}$ and $\mathrm{Er}$ involve only excitation to higher Er energetic levels.

About the dependence of ET efficiency on the Bi content, we can observe that for the lower $\mathrm{Er}$ concentration, $1.1 \mathrm{Er} \%$, the Er related PL emissions increases slightly, about a factor 1.1, by increasing the Bi content from $0.4 \mathrm{Bi} \%$ to $1.0 \mathrm{Bi} \%$, and a weak $\mathrm{Bi} \mathrm{PL}$ emission at $500 \mathrm{~nm}$ is observable for both $\mathrm{Bi}$ concentrations. Instead, for $3.3 \mathrm{Er} \%$, the Er related PL intensities increase by a factor of 1.6 by increasing $\mathrm{Bi}$ concentration and the $\mathrm{Bi}$ PL emission almost disappears. This suggest that for $1.1 \mathrm{Er} \%$ the optimized Er-Bi coupling is reached for the higher Bi content, corresponding to a Er:Bi ratio of almost 2:1: thus increasing further the sensitizers concentration is not beneficial. Instead if we consider the sample containing 3.3 $\mathrm{Er} \%$, the almost disappearance of Bi PL emission suggests that all the $\mathrm{Bi}$ ions introduced in the host transfer their energy non-radiatively to Er ions for both Bi concentrations. Therefore as confirmed by the enhancement of the $\mathrm{Er}$ related PL intensities by increasing $\mathrm{Bi}$ content, from $\mathrm{Er}: \mathrm{Bi}$ of $8: 1$ to $3: 1$, the number of Er ions coupled with Bi is increasing.

A quantitative estimation of the ET efficiency can be done by considering the reduction of PL emission at $500 \mathrm{~nm}$ from $\mathrm{Bi}$ in absence of $\mathrm{Er}$ (in the $\mathrm{Bi}$ doped $\mathrm{Y}_{2} \mathrm{O}_{3}$ thin film), $P L_{B i}$, with respect to the case of $(\mathrm{Er}+\mathrm{Bi})$ copresence (in the (Er+Bi) co-doped $\left.\mathrm{Y}_{2} \mathrm{O}_{3}\right) . P L_{B i+E r}$, for a fixed $\mathrm{Bi}$ content [42]. The formula is

$$
\eta_{E T}=1-\frac{P L_{B i+E r}}{P L_{B i}}
$$

A value of about $70 \%$ and $98 \%$ have been estimated for $1.1 \mathrm{Er} \%$ and $3.3 \mathrm{Er} \%$ respectively.

\section{Dependence of optical properties on pump flux}

In order to investigate the potentiality of this system in light emitting devices or optical amplifiers at $1540 \mathrm{~nm}$, we have investigated the dependence of optical properties on excitation pump flux, $\Phi$. Indeed in Erdoped materials, the Er PL intensity at $1540 \mathrm{~nm}$ is typically limited at higher pump power by UC phenomena, as schematized in Fig. 4 (b), especially by the so called first order upconversion (UC1), that involves the following mechanism ${ }^{4} \mathrm{I}_{13 / 2}+{ }^{4} \mathrm{I}_{13 / 2} \rightarrow{ }^{4} \mathrm{I}_{15 / 2}+$ ${ }^{4} \mathrm{I}_{9 / 2}$. The occurrence of these up-conversion processes in our samples has been investigated by studying the trend of the PL intensities as a function of the excitation flux, $\Phi$. Both the direct (488nm) and mediated (325nm) (a)

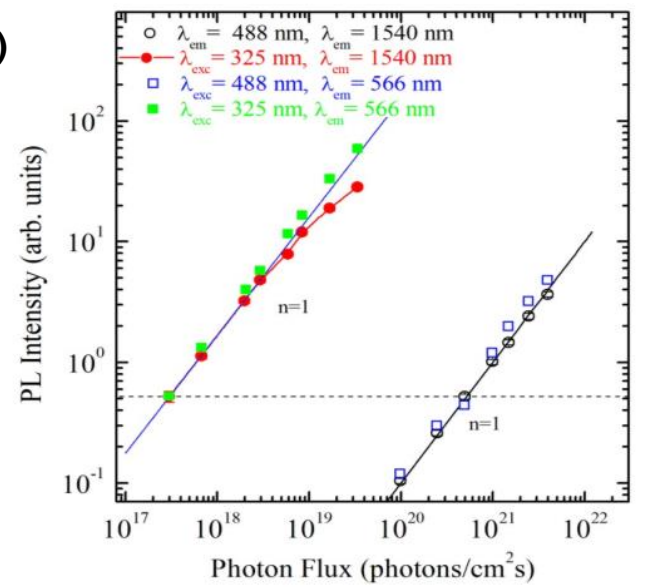

(b)

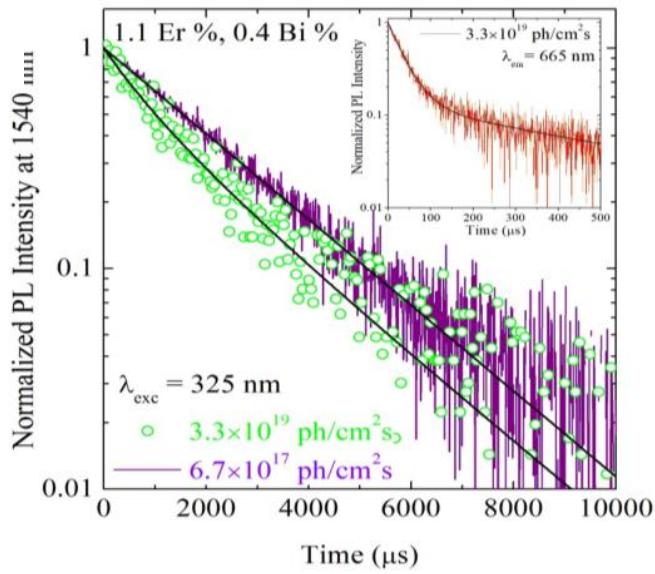

Fig. 5. (a) PL intensity versus photon flux recorded at $566 \mathrm{~nm}$ and at $1540 \mathrm{~nm}$ from $(\mathrm{Er}+\mathrm{Bi})$ co-doped $\mathrm{Y}_{2} \mathrm{O}_{3}$ under 325 (indirect) and $488 \mathrm{~nm}$ (direct) excitation. Linear fits to the PL data are plotted. (b) Time-resolved PL recorded at $1540 \mathrm{~nm}$ under $325 \mathrm{~nm}$ at different pump fluxes. Insert: time-resolved PL measurement at $660 \mathrm{~nm}$ under higher pump fluxes at $325 \mathrm{~nm}$.

(325 nm) excitation conditions have been considered: in particular the flux range was varied from $10^{19} \mathrm{ph} / \mathrm{cm}^{2} \mathrm{~s}$ to $10^{21} \mathrm{ph} / \mathrm{cm}^{2} \mathrm{~s}$ and from $10^{17} \mathrm{ph} / \mathrm{cm}^{2} \mathrm{~s}$ to $10^{19} \mathrm{ph} / \mathrm{cm}^{2} \mathrm{~s}$, respectively for the $488 \mathrm{~nm}$ and $325 \mathrm{~nm}$ excitation wavelength. Owing to the similar PL behaviour of the (Er+Bi) co-doped $\mathrm{Y}_{2} \mathrm{O}_{3}$ samples containing different $\mathrm{Er}$ and $\mathrm{Bi}$ concentrations, from now on we will focus on the case of $1.1 \mathrm{Er} \%$ and $0.4 \mathrm{Bi} \%$ and we will use also the $\mathrm{Bi}$ doped $\mathrm{Y}_{2} \mathrm{O}_{3}$ thin film, as reference, in order to discern eventual influence coming from $\mathrm{Bi}$ ions. Fig. 5 (a) compares the PL trends of the green emission and the $1540 \mathrm{~nm}$ intensity as a function of $\Phi$, both under $488 \mathrm{~nm}$ and $325 \mathrm{~nm}$ excitation. Even if not displayed in the figure, it is important to point out that the Bi PL emission in the $\mathrm{Bi}$ doped $\mathrm{Y}_{2} \mathrm{O}_{3}$ thin film increases linearly in all the investigated range. It means that the $\mathrm{Bi}$ emission is due to the absorption of only one photon in all the investigated flux range. To fit the trends of Er emission in $(\mathrm{Er}+\mathrm{Bi})$ co-doped $\mathrm{Y}_{2} \mathrm{O}_{3}$, the relation $\mathrm{I}_{\mathrm{PL}}$ $\propto \Phi^{n}$, where $n$ is the number of photons absorbed [45], was used. The fits are reported in the same figure as well. The same linear trend has been recorded for all the observed Er emission peaks in $(\mathrm{Er}+\mathrm{Bi})$ co-doped $\mathrm{Y}_{2} \mathrm{O}_{3}$ under $488 \mathrm{~nm}$ excitation. Fig. 5 (a) reports only 
the trend of Er emission at $1540 \mathrm{~nm}$ (black empty dots) and at $566 \mathrm{~nm}$ (green full squares) as examples. Instead, under mediated excitation similar PL intensities have been reached for three orders of magnitude lower $\Phi$. The PL emission peaked at $1540 \mathrm{~nm}$ follows a linear behaviour only for fluxes lower than $3 \times 10^{18} \mathrm{ph} / \mathrm{cm}^{2} \mathrm{~s}$ $(n=1)$ and then it becomes sub-linear $(n<1)$. It means that for higher fluxes the $\operatorname{Er}{ }^{4} \mathrm{I}_{13 / 2}$ energy level is partially depleted by the occurrence of one or more upconversion mechanisms. However, the trend of the $566 \mathrm{~nm}$ emission preserves the linear behaviour, as can be seen in Fig. 5 (a) in the green squared curve, as well as the one concerning the $980 \mathrm{~nm}$ emission (not shown).

The occurrence of UC1 is also confirmed by the decay curves as shown in Fig. 5 (b) that reports the lifetime recorded at $1540 \mathrm{~nm}$ for two different photon fluxes, $3 \times 10^{17} \mathrm{ph} / \mathrm{cm}^{2} \mathrm{~s}$ (low excitation $\Phi$, linear regime) and $3 \times 10^{19} \mathrm{ph} / \mathrm{cm}^{2} \mathrm{~s}$ (high excitation $\Phi$, sublinear regime), under $325 \mathrm{~nm}$ excitation. At the higher excitation flux, the curve is characterized by a faster decay in the first instants, while a simple exponential decay is observed for the lower one. Both curves follow the same parallel decay for longer times. It suggests a depletion of the ${ }^{4} \mathrm{I}_{13 / 2}$ energy level due to up-conversion mechanisms. However, the decay times of the ${ }^{4} S_{3 / 2}$ (emission at $566 \mathrm{~nm}$ ) and of the ${ }^{4} \mathrm{I}_{11 / 2}$ (emission at $980 \mathrm{~nm}$ ) energy levels (not shown) are not affected by the $\Phi$, as expected by the linear trend of the respective PL intensities, thus excluding the occurrence of the upconversion processes involving these levels [14]. Values of about $25 \mu$ s and $800 \mu$ s have been found for the $566 \mathrm{~nm}$ and $980 \mathrm{~nm}$ emissions, respectively, independently by the excitation conditions, and comparable with the values reported for similar systems $[14,46]$. The only decay curve that changed in the high pumping regime is the one corresponding to the $660 \mathrm{~nm}$ emission. As it can be seen in the inset of Fig. 5 (b), for high photon flux the lifetime shows two distinct components. The fastest one is independent of the $\Phi$ and has a value of about $38 \mu \mathrm{s}$, representing the characteristic lifetime of the ${ }^{4} F_{9 / 2}$ energy level. The much slower component appears only for highest pump flux and it has a value of about $500 \mu \mathrm{s}$. It can be associated to the UP mechanism depicted in Fig. 4 (b) [47] that becomes more probable for higher excitation fluxes. It involves two neighbouring Er ions excited in the ${ }^{4} I_{13 / 2}$ and ${ }^{4} I_{11 / 2}$ energy levels, respectively. The energy emitted non-radiatively by the first one to reach the ground state can be absorbed by the second one, which is promoted to the ${ }^{4} F_{9 / 2}$ level by an exchange of 3 phonons [47]. This explains also why the observed slow component in the decay time $(0.5 \mathrm{~ms})$ is comparable to the characteristic lifetime of the underlying ${ }^{4} \mathrm{I}_{11 / 2}$ level.

These results demonstrate that PL intensities both in the visible and IR range keep a linear trend for an extended range, up to $3 \times 10^{18} \mathrm{ph} / \mathrm{cm}^{2} \mathrm{~s}$, under $325 \mathrm{~nm}$ excitation.

Moreover, from the comparison of Er linear PL trends under resonant and mediated excitation, it is possible to observe that under mediated excitation we can reach similar PL intensities with respect to the direct excitation but with almost three orders of magnitude lower pump fluxes. Through the fit of these trends we have also estimated the effective excitation cross section in presence of $\mathrm{Bi}$. Indeed in the linear regime, the PL intensity can be approximated by the relation $[5,14]$

$$
I_{P L} \propto \sigma \Phi \frac{\tau}{\tau_{\text {rad }}}
$$

where, $\tau$ is the total lifetime, $\tau_{\text {rad }}$ is the radiative lifetime, and $\sigma$ is the $\mathrm{Er}$ effective excitation cross section. Since the measured $\tau$ does not change by varying the excitation condition (as shown in Fig. 3 (b)), the ratio of the slopes of the two PL trends at 1540 $\mathrm{nm}$ gives the ratio of the effective excitation cross sections under direct $\mathrm{Er}$ absorption, $\sigma_{\mathrm{Er}}$, and under mediated excitation, $\sigma_{\mathrm{Er}+\mathrm{Bi}}$. From the data in Fig. 5 (a), we found that $\sigma_{\mathrm{Er}+\mathrm{Bi}}$ is about 2220 times higher than $\sigma_{\mathrm{Er}}$ [39]. Assuming $\sigma_{\mathrm{Er}}$ equal to $2.4 \times 10^{-21} \mathrm{~cm}^{2}$, we can estimate a $\sigma_{\mathrm{Er}+\mathrm{Bi}}$ value of $5.3 \times 10^{-18} \mathrm{~cm}^{2}$, which is compatible with $10^{-17} \mathrm{~cm}^{2}$, value reported for $\mathrm{Bi}^{3+}$ direct excitation cross section in $\mathrm{BiGeO}$ [48]. This is another confirmation of the very efficient energy transfer between $\mathrm{Bi}^{3+}$ and $\mathrm{Er}^{3+}$ ions in $\mathrm{Y}_{2} \mathrm{O}_{3}$ films; moreover, it is interesting to underline that this value is one of the highest obtained for Er in Si compatible hosts $[43,44]$.

\section{Conclusion}

In conclusion, we have demonstrated the great potentialities of $(\mathrm{Er}+\mathrm{Bi})$ co-doped thin film as silicon compatible light emitter both in the visible and IR region. The structural characterization and the PL measurements have been evidenced the good dopants dissolution and the optical activities of both dopants in this host. In particular the ET efficiency between Bi and Er have been evaluated and the best $\mathrm{Er}$ and $\mathrm{Bi}$ ratio have been found in order to maximize the PL emission in the visible and IR range. Also, the optical properties have been confirmed in an extended flux range. Finally, the effective Er excitation cross section by Bi ET have been estimated to be 2200 times higher than the direct excitation, by reaching the highest values observed in literature. These results make this material very promising as an efficient visible emitter and a Sicompatible optical amplifier at $1540 \mathrm{~nm}$.

\section{Acknowledgements}

This work was supported by of Italian Ministry for Education, University and Research (MIUR) through the PON project "Bionanotech Research and Innovation Tower" (BRIT) is acknowledged. The authors want to thank G. Franzò for useful discussions, and C. Percolla, S. Tatì and G. Pantè for expert technical assistance.

\section{Author's contributions}

A.S. realized the Bi-doped yttrium oxide thin films and performed all the structural and optical characterizations; she contributed to data interpretation and wrote the paper. R.R. supervised the optical characterization. F.P. contributed to supervise the experiments, the data interpretation and the paper writing. M.M. conceived and supervised the project, interpreted data and wrote the paper. All authors participated to data discussion, reviewed the manuscript and approved its submission. 


\section{References}

1. Kirchain, R.; Kimerling, L.C., Nat. Photonics, 2007, 1, 303.

2. Priolo, F.; Gregorkiewicz, T.; Galli, M.; Krauss, T.F., Nat. Nanotechnol., 2014, 9, 19

3. Kenyon, A. J., Semicond. Sci. Technol., 2005, 20, R65.

4. Ramirez, J. M.; Lupi, F. F.; Jambois, O.; Berencen, Y.; Navarro-Urrios, D.; Anopchenko, A.; Marconi, A.; Prtljaga, N.; Tengattini, A.; Pavesi, L.; Colonna, J.P.; Fedeli, J. M.; Garrido, B., Nanotechnology, 2012, 23, 125203.

5. Miniscalco, W. J., J. Light. Technol., 1991, 9, 234.

6. Polman, A., J. Appl. Phys., 1997, 82, 1.

7. Wang, X. J.; Yuan, G.; Isshiki, H.; Kimura, T.; Zhou, Z., J. Appl. Phys. Lett., 2010, 108, 013506.

8. Suh, K.; Shin, J. H.; Seo, S. J.; Bae, B.S., Appl. Phys. Lett., 2008, 92, 121910.

9. Wang, X.; Zhou, P.; He, Y.; Zhou, Z., Opt. Mater. Expr., 2018, 8, 2970.

10. Sun, H.; Yin, L.; Liu, Z.; Zheng, Y.; Fan, F.; Zhao, S.; Feng, X.; Li, Y.; Ning, C. Z., Nat. Phot., 2017, 11, 589.

11. Miritello, M.; Lo Savio, R.; Iacona, F.; Franzò, G.; Irrera, A.; Piro, A.M.; Bongiorno, C.; Priolo, F., Adv. Mater., 2007, 1, 1582 .

12. Snoeks, E.; Kik, P.G.; Polman, A., Opt. Mater. 1996, 5, 159.

13. Miritello, M.; Cardile, P.; Lo Savio, R.; Priolo, F., Opt. Express, 2011, 19, 20761.

14. Lo Savio, R.; Miritello, M.; Cardile, P.; Priolo, F., J. Appl. Phys., 2009, 106, 043512.

15. Evangelou, E.K.; Wiemer, C.; Fanciulli, M.; Sethu, M.; Cranton, W., J. Appl. Phys., 2003, 94, 318.

16. Irrera, A.; Artoni, P.; Iacona, F.; Pecora, E.F.; Franzò, G.; Galli, M.; Fazio, B., Nanotechnology, 2012, 23, 075204.

17. Izeddin, I.; Timmerman, D.; Gregorkiewicz, T.; Moskalenko, A.S.; Prokofiev, A. A.; Yassievich, I.N.; Fujii, M., Phys. Rev. B, 2008, 78, 035327.

18. Cardile, P.; Miritello, M.; Priolo, F., Appl. Phys. Lett., 2012 , 100, 251913.

19. Cao, R.; Fu, T.; Cao, Y.; Ao, H.; Guo, S.; Zheng, G., Mater. Lett., 2015, 155, 68.

20. Huang, M. N.; Ma, Y. Y.; Huang, X. Y.; Ye, S.; Zhang, Q. Y., Spectra Acta Part A: Mol. Biomol. Spectr. 2013, 115, 767.

21. Tabaza, W. A. I.; Swart, H. C.; Kroon, R.E., J. Lumin., 2014 148, 192.

22. Peng, M.; Zhang, N.; Wondraczek, L.; Qiu, J.; Yang, Z.; Zhang, Q., Opt. Express 2011, 19, 20799.

23. Hau, T.M.; Yu, X.; Zhou, D.; Song, Z.; Yang, Z.; Wang, R.; Qiu, J., Opt. Mater., 2013, 35, 487.

24. Bai, Z.; Sun, H.T.; Hasegawa, T.; Fujii, M.; Shimaoka, F.; Miwa, Y.; Mizuhata, M.; Hayashi, S., Opt. Lett., 2010, 35, 1926.

25. Zheng, J. ; Zuo, Y. H.; Zhang, L.Z.; Wang, W.; Xue, C. L.; Cheng, B.W.; Yu, J. Z.; Guo, H. Q.; Wanga, Q. M., J. Lumin., 2010, 130, 1760

26. Ziegler, J.; Ziegler, M.D.; Biersack, J.P.; SRIM - The stopping and range of ions in matter, Nucl. Instrum. Methods B 2010, 268, 1818.

27. Mayer, M.; SIMNRA 6.03 simulation program (1997-2006).

28. Scarangella, A.; Miritello, M.; Priolo, F., J. Appl. Phys., 2014, $116,123511$.

29. Scarangella, A.; Reitano, R.; Priolo, F.; Miritello, M., Mat. Sci Semicon. Proc., 2018 in Press. DOI: $10.1016 /$ j.mssp.2018.04.017

30. Card JCPDS No. 41-1105.

31. Vetrone, F.; Boyer, J.C.; Capobianco, J.A.; Speghini, A.; Bettinelli, M., Chem. Mater., 2003, 15, 2737.

32. Camargo, M. B.; Gomes, L.; Morato, S. P., Opt. Mater., 1995 , $4,597$.

33. Zhou, S.; Jiang, N.; Zhu, B.; Yang, H.; Ye, S.; Lakshminarayana, G.; Hao, J.; Qiu, J., Adv. Funct. Mater. 2008 , 18, 1407.

34. Fujimoto Y.; Nakatsuka, M., J. Appl. Phys. 2001, 40, L279.

35. Wu, X.; Liang, Y.; Chen, R.; Liu, M.; Li, Y., J. Mater. Sci. 2011, 46, 5581 .
36. Scarangella, A.; Fabbri, F.; Reitano, R.; Rossi, F.; Priolo, F.; Miritello, M., Sci. Rep., 2017, 7, 17325.

37. Jacobsohn, L. G., et al.; J. Appl. Phys. 2008, 104, 124303.

38. Van de Craats, A. M. ; Blasse, G., Chem. Phys. Lett., 1995, 243, 559.

39. Scarangella, A.; Reitano, R.; Franzò, G.; Priolo, F. \& Miritello, M., Appl. Phys. Lett., 2015, 107, 041908.

40. Wu, X.; Liang, Y.; Chen, R.; Liu, M.; Li, Y., J. Mater. Sci., 2011, 46, 5581.

41. Scarangella, A.; Reitano, R.; Franzò, G.; Priolo, F.; Miritello, M., J. Lumin., 2017, 191, 92.

42. Charbonniére, L. J.; Hildebrandt, N.; Eur. J. Inorg. Chem., 2008, 3241

43. Daldosso et al., Laser \& Photon. Rev., 2009, 3, 508.

44. Priolo F.; et al., J. Appl. Phys., 2001, 89, 264.

45. Pollnau, M.; Gamelin, D. R.; Lüthi, S. R.; Güdel, H. U.; Hehlen, M. P.; Phys. Rev. B, 2000, 61, 3337.

46. Capobianco, J.A.; Vetrone, F.; D’Alesio, T.; Tessari, G.; Speghini, A.; Bettinelli, M., Phys. Chem., 2000, 2, 3203.

47. Guo, H.; Qiao, Y. M., Opt. Mater., 2009, 31, 583.

48. Weber, M. J.; Monchamp, R. R., J. Appl. Phys. 1973, 44, 5495. 